\title{
Friction and Wear Characteristics of Rubber Resin-Bonded Metallic Brake Pad Materials
}

\author{
Kishor N. Hendre, Bhanudas D. Bachchhav
}

\begin{abstract}
This paper aims to present comparative study of friction and wear characteristics of non-asbestos rubber resin bonded metallic based brake pad material. Friction material was compression moulded and machined to a sample size. Their physical and mechanical properties were studied. Experiments were conducted using Pin-on-disc test set-up against EN31 disc. Coefficient of friction and wear was measured for metallic based brake materials at varying conditions of temperature, sliding velocity, pressure and sliding distance. When brake pads are in contact with brake disc, heat is generated hence thermal behaviour of metallic based brake material and its impact on friction and wear were studied. Experiments, based on Taguchi's analysis technique, using $L_{9}$ orthogonal array were performed. On the basis of experimental results and $S / N$ ratio analyses, ranking of the parameters have been done. It was found that temperature (95.37\%) and sliding velocity (2.99\%) are most affecting parameters in friction, However temperature (82.96 \%) and pressure (6.80) in wear. The elemental composition of metallic based brake material was measured by EDS technique. SEM micrographs of brake pad samples were tested at different magnifications. Further detailed studies are suggested to evaluate wear rate, stopping distance under simulative test conditions alternate to asbestos based brake pad material.
\end{abstract}

Index Terms: Asbestos-free, Metallic Brake Pad Materials, Friction and Wear, Pin-on-Disc Test, Taguchi Method

\section{INTRODUCTION}

A brake pad / lining is the most important element of the automotive disc brake system. Brake linings are the sacrificial wearing elements and the primary determinants of frictional behavior, therefore brake pad materials should maintain a controlled friction coefficient, minimum wear and good thermal conductivity [1]-[2]. Asbestos based friction materials have been used over a century but presently being banned because of its health hazards. A lot of research is being carried out in developing eco-friendly brake pad materials having equally good mechanical, thermal and tribological properties to that of asbestos [3]-[4]. The friction material usually composed of binders, reinforcements,

Revised Manuscript Received on October 30, 2019.

* Correspondence Author

Kishor N. Hendre*, PG Scholar, Department of Mechanical Engineering, All India Shri Shivaji Memorial Society's, College of Engineering, Pune, Maharashtra, India. Email: kishorhendre77@gmail.com Bhanudas D. Bachchhav, Prof. and Head, Department of Mechanical Engineering, All India Shri Shivaji Memorial Society's, College of Engineering, Pune, Maharashtra, India. Corresponding Author E

mail: bdbachchhav@aissmscoe.com, bhanudas2k@gmail.com

(C) The Authors. Published by Blue Eyes Intelligence Engineering and Sciences Publication (BEIESP). This is an open access article under the CC BY-NC-ND license (http://creativecommons.org/licenses/by-nc-nd/4.0/) friction modifiers and fillers; however their composition keep changing with applications, technological developments and impending environmental impact. Development of asbestos-free friction materials from agro-waste, composites and with no copper and lead have been carried out [5]-[8]. Comparison of mechanical and physical properties of newly developed materials with other commercial brake pad materials and their performance evaluation was discussed. A preliminary investigation has been carried out to evaluate coefficient of friction and wear using pin-on-disc test set-up [9]-[11]. Morphological analysis of friction bands produced during braking operations, area covered by the friction layer on brake disc surface and correlation among temperature variation and morphological analysis were discussed [12] Attempts have been made [13] to grade critical properties for a selection of brake pad materials amongst all by using Analytic Hierarchy Process (AHP) and found that friction coefficient, wear and thermal conductivity are most predominant. However, the analysis primarily was based on qualitative attributes only.In this paper, metallic based friction materials namely AF-22 were compression moulded and machined to a pin sample size. Their physical and mechanical properties were studied for comparison purpose. This paper highlights the investigations of frictional and wear characteristics of these materials in order to render it a suitable material for brake pad application through detailed quantitative analysis using Taguchi method [14].

\section{AF-22 BRAKE PAD FRICTION MATERIAL}

Friction material were procured from CO-EFF friction bands, India under the trade name AF-22 having density 2.12 $\mathrm{g} / \mathrm{cm}^{3}$, compressive strength $165 \mathrm{~N} / \mathrm{mm}^{2}$ and transverse bending strength $78 \mathrm{~N} / \mathrm{mm}^{2}$. AF-22 brake pad material made up of non-asbestos friction material, rubber resin bonded, metallic filler based. Brake friction material sample were crushed into the fine powder sample for energy dispersive spectroscopy (EDS) and scanning electron microscopy (SEM) analysis. When brakes applied at that time heat is generated and brake material heats, to study the thermal behavior of braking materials thermogravimetry analysis (TGA) used.

\section{A. AF-22 Brake Pad Friction Materials}

The elemental composition, as measured by EDS is reported in Table 1. Major elements found are C (Carbon), Si (Silicon), Ba (Barium), Sb (Antimony). It also includes elemental properties of Ca (Calcium) and Mo (Molybdenum) in AF-22 brake pad material sample. 
Table 1. Elemental Composition by EDS for AF-22 Material

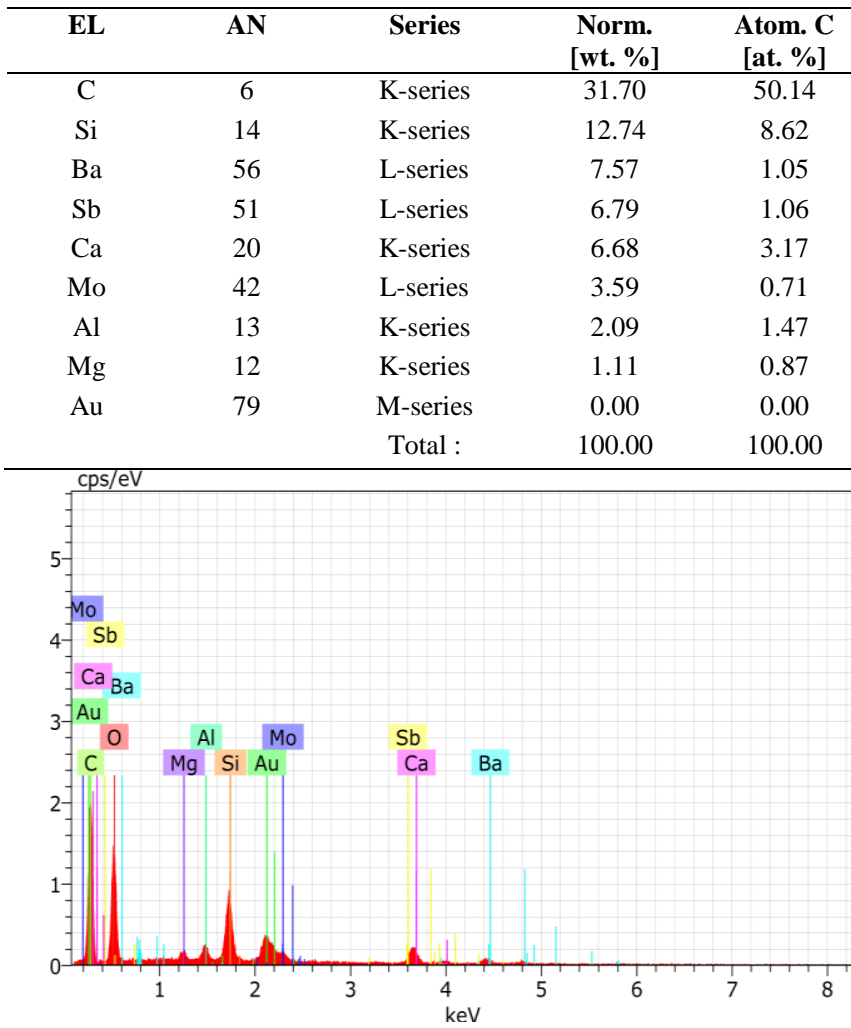

Fig 1. EDS Spectrum as Detected for AF-22 Brake Pad Material Sample

Figure 1 shows EDS spectrum and elemental composition of AF-22 material. It contains ingredients like $\mathrm{C}, \mathrm{Si}, \mathrm{Ba}, \mathrm{Sb}$, $\mathrm{Ca}, \mathrm{Mo}, \mathrm{Al}$ etc.

\section{B. Microstructure Studies by SEM}

SEM image shows chunk, segments and block images of AF-22 compound in Figure 2a at 2000 x magnifications. Due to the presence of rubber resin, $\mathrm{C}$ (Carbon) and Si (Silicon) wt (\%) are higher like carbon provides hydrocarbon close fit bonding for higher strength. This AF-22 brake pad material sample brittle and flaky due to presence of properties $\mathrm{Ca}$ and Sb in Figure 2b at 50000 x magnifications.

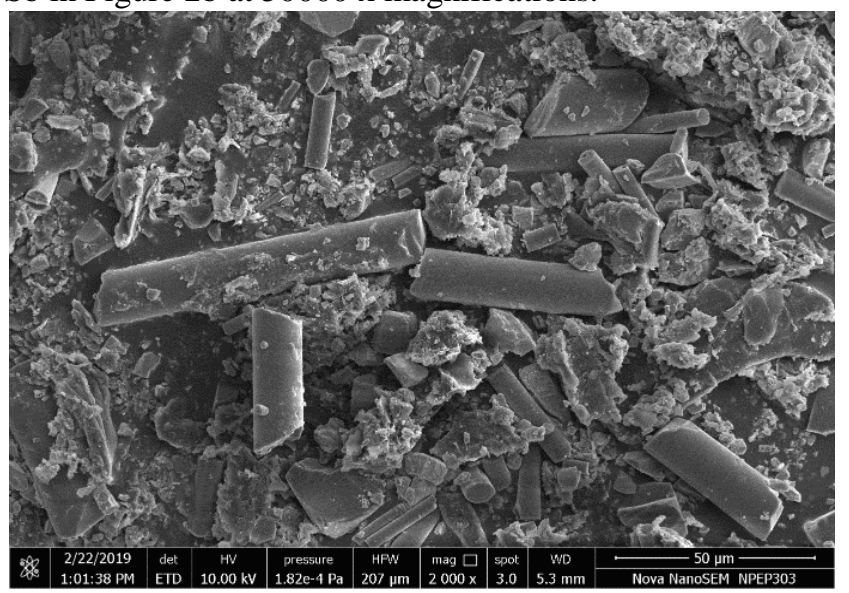

Fig. 2a. SEM Image of AF-22 Brake Material Sample at 2000 x Magnifications

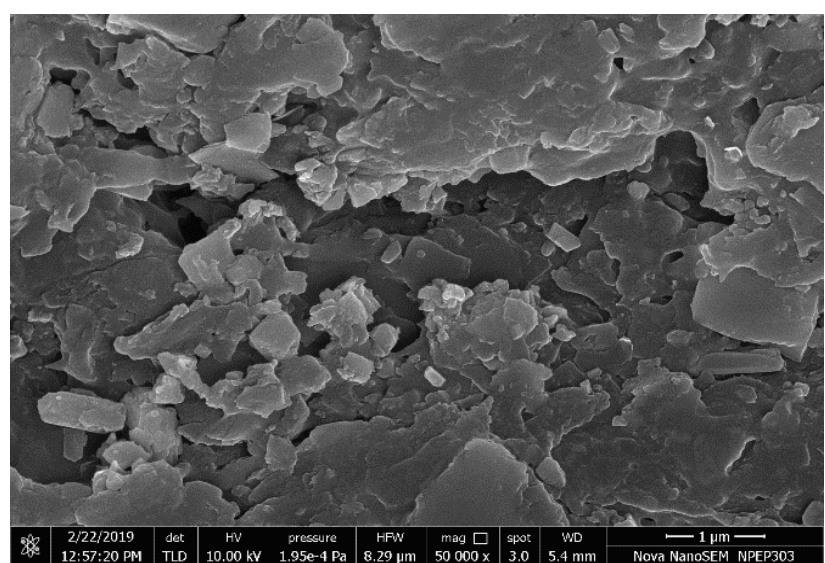

Fig. 2b. SEM Image of AF-22 Brake Material Sample at $50000 \times$ Magnifications

\section{Thermogravimetry Analysis}

To study the thermal behaviour of metallic brake material at elevated temperature thermogravimetry analysis is used.

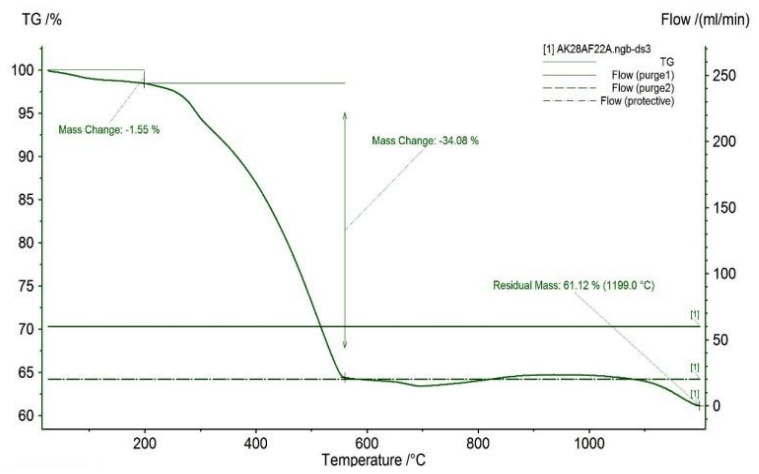

Fig. 3. Thermal Analysis of AF-22 Brake Material

A typical result for a thermo-gravimetric analysis of the AF-22 friction material in an oxygen rich atmosphere as shown in Figure 3. The main thermal event is preceded by a slow and steady thermal degradation accounting for a $1.55 \%$ mass loss before the onset temperature of $200{ }^{\circ} \mathrm{C}$. Between $600{ }^{\circ} \mathrm{C}$ and $800{ }^{\circ} \mathrm{C}$ the oxidation of metallic compounds within the formulation such as carbon, silicon and antimony produces a gain in mass once the main thermal degradation event subsides shown in Figure 3.

\section{EXPERIMENTATION}

Experiments were conducted using DUCOM (TR-20LE) test-rig working on the "Pin-on-disc" principle at elevated temperature. A schematic diagram for pin-on-disc set-up shown in Figure 4. Pin is of 8-mm diameter, made up of AF-22 brake pad material ground and flattened on its bottom surface. The counter-face disc used is of steel hardened to 60 HRC, 165-mm diameter and 8-mm thick, which is rotating through a driven spindle, a lever arm device to hold the pin and attachments to allow the pin to be forced against the revolving disc with a controlled load. The tangential force exerted by the disc on the pin is measured by the beam-type load cell connected to the indicator. 
Parameters which correspond to actual braking operation, like sliding speed of disc, brake pad holding pressure, temperature etc., were considered into their realistic range for the experimental study.

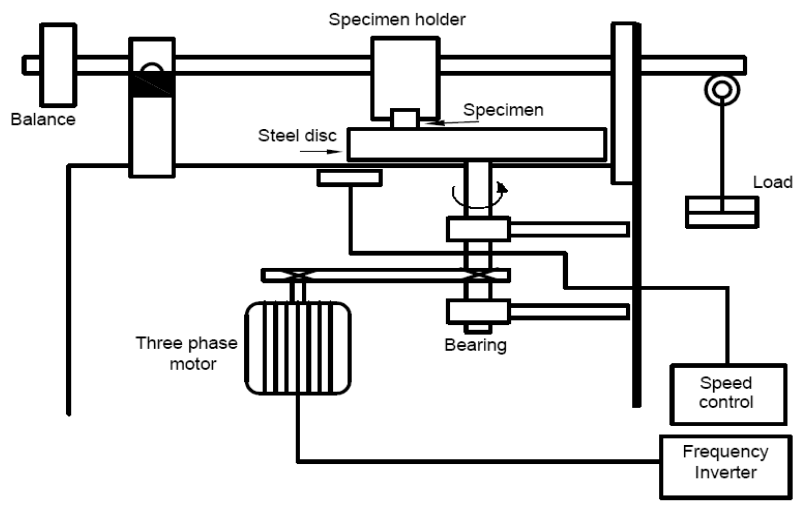

Fig. 4. Schematic Diagram of Pin on Disc Set-Up

\section{A. Plan of Experiments}

For elaboration of experiments, authors used Taguchi's method for four factors at three levels. Table 2 indicates the factors assigned and the corresponding levels for experiments. In Table 3, the plan of experiments was made based on $L_{9}$ orthogonal array and the response studied was coefficient of friction $(\mu)$ and wear rate.

Table 2. Assignment of the Levels to the Factors

\begin{tabular}{|c|c|c|c|}
\hline \multicolumn{4}{|c|}{ Levels } \\
\hline Factors & 1 & 2 & 3 \\
\hline Temperature $(\mathrm{T}){ }^{0} \mathrm{C}$ & 50 & 100 & 150 \\
\hline Sliding Velocity (V) m/s & 2.1 & 4.2 & 6.3 \\
\hline Pressure (P) N/mm² & 1 & 2 & 3 \\
\hline Sliding Distance (D) m & 4000 & 8000 & 12000 \\
\hline
\end{tabular}

Table 3. Experimental Results

\begin{tabular}{|c|c|c|c|c|c|c|c|c|c|c|}
\hline \multirow{2}{*}{$\begin{array}{l}\mathbf{R} \\
\mathbf{U} \\
\mathbf{N}\end{array}$} & \multicolumn{4}{|c|}{ Levels } & \multicolumn{3}{|c|}{ Coefficient of Friction } & \multicolumn{3}{|c|}{$\begin{array}{l}\text { Wear Rate*10^-5 } \\
\text { mm³ }^{3} / \mathrm{Nm}\end{array}$} \\
\hline & $\mathbf{T}$ & $\mathbf{V}$ & $\mathbf{P}$ & D & $\mu_{1}$ & $\mu_{2}$ & $\begin{array}{c}\text { S/N } \\
\text { Ratio }\end{array}$ & $\mathbf{W R}_{1}$ & $\mathbf{W R}_{2}$ & $\begin{array}{r}\text { S/N } \\
\text { Ratio }\end{array}$ \\
\hline 1 & 50 & 2.1 & 1 & 4000 & 0.44 & 0.47 & -6.853 & 1.17 & 1.16 & -1.32 \\
\hline 2 & 50 & 4.2 & 2 & 8000 & 0.45 & 0.48 & -6.664 & 1.45 & 1.46 & -3.25 \\
\hline 3 & 50 & 6.3 & 3 & 12000 & 0.46 & 0.49 & -6.479 & 1.54 & 1.54 & -3.75 \\
\hline 4 & 100 & 2.1 & 2 & 12000 & 0.50 & 0.50 & -6.020 & 2.16 & 2.15 & -6.66 \\
\hline 5 & 100 & 4.2 & 3 & 4000 & 0.49 & 0.51 & -6.025 & 2.34 & 2.33 & -7.36 \\
\hline 6 & 100 & 6.3 & 1 & 8000 & 0.49 & 0.52 & -5.945 & 2.81 & 2.81 & -8.97 \\
\hline 7 & 150 & 2.1 & 3 & 8000 & 0.52 & 0.53 & -5.598 & 1.01 & 1.01 & -0.08 \\
\hline 8 & 150 & 4.2 & 1 & 12000 & 0.50 & 0.54 & -5.699 & 4.15 & 4.16 & -12.3 \\
\hline 9 & 150 & 6.3 & 2 & 4000 & 0.51 & 0.55 & -5.533 & 4.10 & 4.10 & -12.2 \\
\hline
\end{tabular}

\section{FRICTIONAL CHARACTERISTICS OF AF-22 BRAKE MATERIAL}

Experiments conducted with the aim of relating the influence of temperature, sliding velocity, pressure and sliding distance with the coefficient of friction $(\mu)$ for ranking, they based on their contribution.
Table 4. Response Table of Coefficient of Friction for S/N Ratio.

\begin{tabular}{ccccc}
\hline Level & $\begin{array}{c}\text { Temperature } \\
\mathbf{( T )}\end{array}$ & $\begin{array}{c}\text { Sliding } \\
\text { Velocity } \\
(\mathbf{V})\end{array}$ & $\begin{array}{c}\text { Pressure } \\
\mathbf{( P )}\end{array}$ & $\begin{array}{c}\text { Sliding } \\
\text { Distance } \\
(\mathbf{D})\end{array}$ \\
\hline 1 & -6.666 & -6.158 & -6.166 & -6.138 \\
2 & -5.997 & -6.130 & -6.073 & -6.069 \\
3 & -5.610 & -5.986 & -6.034 & -6.066 \\
Delta & 1.056 & 0.172 & 0.132 & 0.071 \\
Rank & 1 & 2 & 3 & 4 \\
\hline
\end{tabular}

The tests were replicated twice, resulting in total 18 observations, to allow the analysis of the variance of the results and $\mathrm{S} / \mathrm{N}$ ratios. Table 4 shows response for $\mathrm{S} / \mathrm{N}$ ratios.

\section{A. Main Effect Plot for S/N Ratio}

For main effect plot signal to noise ratio was consider as larger is better for coefficient of friction shown in Figure 5.

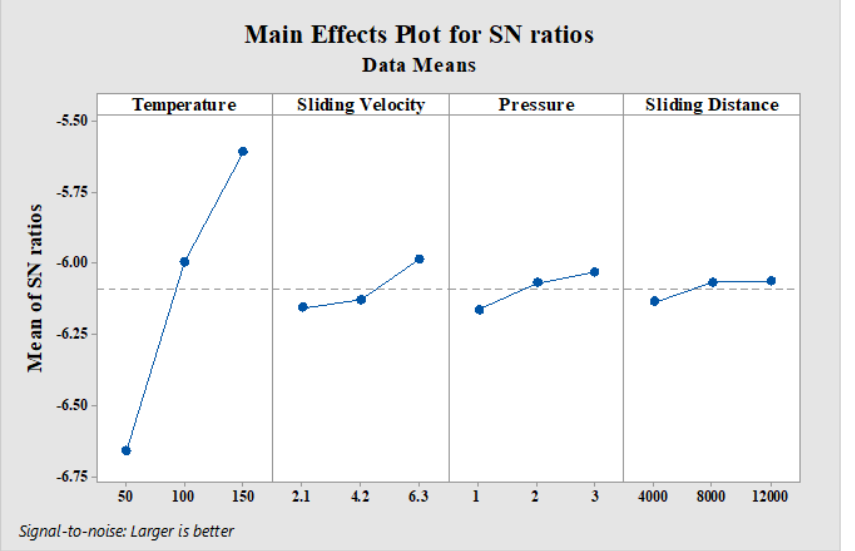

Fig 5. Main Effect Plot of Coefficient of Friction for SN Ratio

\section{B. Analysis of Variance and (ANOVA) S/N Ratio}

The signal-to-noise ratio $(\mathrm{S} / \mathrm{N})$ expresses the scatter around a target value. The larger the ratio, the smaller the scatter. Taguchi's loss function can be express in terms of mean square deviation (MSD), and thus $\mathrm{S} / \mathrm{N}$ ratios. Here, in braking operation the coefficient of friction is desire to be larger and wear rate smaller hence larger $\mathrm{S} / \mathrm{N}$ ratio as a better condition is considered for coefficient of friction and the equations (1) and (2) for the same given below [15].

$$
\mathrm{S} / \mathrm{N}=-10_{\log }(\mathrm{MSD})
$$

Where MSD = mean square deviation. For larger is better:

$$
\operatorname{MSD}=\left(\mathrm{y}_{1}{ }^{2}+\mathrm{y}_{2}{ }^{2}+\mathrm{y}_{3}{ }^{2}+-----\mathrm{y}_{\mathrm{n}}{ }^{2}\right) / \mathrm{n}
$$

Where $\mathrm{n}$ is the number of observations and $\mathrm{y}$ is the observed data.

Using MINITAB, Taguchi design software, $\mathrm{S} / \mathrm{N}$ ratios for coefficient of friction, ranking of parameters and ANOVA are calculated and shown in Table 4 and 5, respectively. Contribution percentage of influencing factors calculated based on pure sum of squares. 
Table 5. ANOVA for Coefficient of Friction $(\mu)$

\begin{tabular}{|l|c|c|c|c|c|c|}
\hline Source & DF & Seq SS & Adj MS & Adj SS & $\begin{array}{c}\text { P-Val } \\
\text { ue }\end{array}$ & $\begin{array}{c}\text { (\%) } \\
\text { Cont }\end{array}$ \\
\hline $\begin{array}{l}\text { Temperat } \\
\text { ure }\end{array}$ & 2 & 0.00548 & 0.002744 & 0.005489 & 0.000 & 95.37 \\
\hline $\begin{array}{l}\text { Sliding } \\
\text { Velocity }\end{array}$ & 2 & 0.00017 & 0.000086 & 0.000172 & 0.000 & 2.99 \\
\hline Pressure & 2 & 0.00007 & 0.000036 & 0.000072 & 0.000 & 1.25 \\
\hline $\begin{array}{l}\text { Sliding } \\
\text { Distance }\end{array}$ & 2 & 0.00002 & 0.000011 & 0.000022 & 0.000 & 0.39 \\
\hline Error & 0 & 0.00000 & 0.000000 & 0.000000 & 0.000 & 0.00 \\
\hline Total & 8 & 0.00575 & & & & 100.0 \\
\hline
\end{tabular}

\section{Regression Analysis for Coefficient of Friction}

Mathematical equation for coefficient of friction in terms of temperature, sliding velocity, pressure and sliding distance obtained from regression analysis using MINITAB software. Equation (3) obtained is as follows:

Coefficient of Friction $(\mu)=0.41722+0.000600 \mathrm{~T}+$ $0.00238 \mathrm{~V}+0.00333 \mathrm{P}+0.000000 \mathrm{D}$

\section{Confirmation Test for Coefficient of Friction}

Table 6 shows the comparison between the results obtained from experiments and results calculated from regression equation. From the Table 6, It has been observed that average error is below $10 \%$, suggesting that validity of derived equation with reasonable degree of freedom.

Table 6. Confirmation Test for AF-22 Brake Material

\begin{tabular}{cccccccc}
\hline Test & $\mathbf{T}$ & $\mathbf{V}$ & $\mathbf{P}$ & $\mathbf{D}$ & \multicolumn{2}{c}{ Coefficient of Friction $(\boldsymbol{\mu})$} & $\begin{array}{c}\text { Relative } \\
\text { Error } \\
\end{array}$ \\
& & & & Experimental & $\begin{array}{c}\text { Regression } \\
\text { Eq. }\end{array}$ & $\mathbf{( \% )}$ \\
\hline 1 & 50 & 2.10 & 1 & 4000 & 0.44 & 0.4555 & 3.88 \\
2 & 50 & 4.20 & 2 & 8000 & 0.45 & 0.4638 & 3.08 \\
\hline
\end{tabular}

\section{WEAR CHARACTERISTICS OF AF-22 BRAKE MATERIAL}

Experiments conducted with the aim of relating the influence of temperature, sliding velocity, pressure and sliding distance with the wear rate for ranking, they based on their contribution.

Table 7. Response Table of Wear Rate for S/N Ratio.

\begin{tabular}{ccccc}
\hline Level & $\begin{array}{c}\text { Temperature } \\
(\mathbf{T})\end{array}$ & $\begin{array}{c}\text { Sliding } \\
\text { Velocity }(\mathbf{V})\end{array}$ & $\begin{array}{c}\text { Pressure } \\
\mathbf{( P )}\end{array}$ & $\begin{array}{c}\text { Sliding } \\
\text { Distance (D) }\end{array}$ \\
\hline 1 & -6.241 & -6.473 & -6.447 & -6.460 \\
2 & -6.656 & -6.504 & -6.545 & -6.545 \\
3 & -6.682 & -6.601 & -6.587 & -6.574 \\
Delta & 0.442 & 0.127 & 0.141 & 0.114 \\
Rank & 1 & 3 & 2 & 4 \\
\hline
\end{tabular}

The tests were replicated twice, resulting in total 18 observations, to allow the analysis of the variance of the results and $\mathrm{S} / \mathrm{N}$ ratios. Table 7 shows response for $\mathrm{S} / \mathrm{N}$ ratios.

\section{A. Main Effect Plot for S/N Ratio}

For main effect plot signal to noise ratio was consider as smaller is better for wear rate shown in Figure 6.

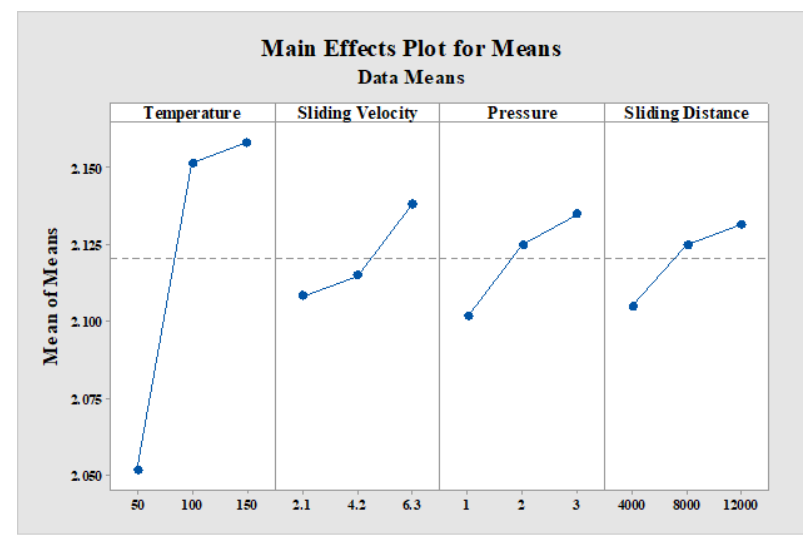

Fig. 6 Main Effect Plot of Wear Rate for SN Ratio

\section{B. Analysis of Variance (ANOVA) and S/N Ratio}

The signal-to-noise ratio (S/N) expresses the scatter around a target value. Using MINITAB, Taguchi design software, $\mathrm{S} / \mathrm{N}$ ratios for wear rate, ranking of parameters and ANOVA are calculated and shown in Table 7 and 8, respectively. Contribution percentage of influencing factors calculated based on pure sum of squares [15].

Table 8. ANOVA for Wear Rate

\begin{tabular}{lcccccc}
\hline Source & DF & Seq SS & $\begin{array}{c}\text { Adj } \\
\text { MS }\end{array}$ & Adj SS & P-Value & $\begin{array}{c}\text { (\%) } \\
\text { Cont }\end{array}$ \\
\hline Temperature & 2 & 0.0214 & 0.0107 & 0.02142 & 0.000 & $82.96 \%$ \\
Sliding & 2 & 0.0014 & 0.0007 & 0.00148 & 0.000 & $5.77 \%$ \\
$\begin{array}{l}\text { Velocity } \\
\text { Pressure }\end{array}$ & 2 & 0.0017 & 0.0008 & 0.00175 & 0.000 & $6.80 \%$ \\
Sliding & 2 & 0.0011 & 0.0005 & 0.00115 & 0.000 & $4.48 \%$ \\
$\begin{array}{l}\text { Distance } \\
\text { Error }\end{array}$ & 0 & 0.000 & 2.2101 & 0.000 & 0.000 & 0.0000 \\
Total & 8 & 0.0258 & & & & $100.00 \%$
\end{tabular}

\section{Regression Analysis for Wear Rate}

Mathematical equation for wear rate in terms of temperature, sliding velocity, pressure and sliding distance obtained from regression analysis using MINITAB software. Equation (4) obtained is as follows:

Wear Rate $=1.9239+0.001067 \mathrm{~T}+0.00714 \mathrm{~V}+0.0167 \mathrm{P}$ $+0.000003 \mathrm{D}$

\section{Confirmation Test for Wear Rate}

Table 9 shows the comparison between the results obtained from experiments and results calculated from regression equation. From the Table 9, it has been observed that average error is below $10 \%$, suggesting that validity of derived equation with reasonable degree of freedom.

Table 9. Confirmation Test for AF-22 Brake Material

\begin{tabular}{cccccccc}
\hline Test & $\mathbf{T}$ & $\mathbf{V}$ & $\mathbf{P}$ & $\mathbf{D}$ & \multicolumn{2}{c}{ Wear Rate } & $\begin{array}{c}\text { Relative } \\
\text { Error } \\
\end{array}$ \\
& & & & & Experimental & $\begin{array}{c}\text { Regression } \\
\mathbf{( \% )}\end{array}$ & \\
\hline 1 & 50 & 2.10 & 1 & 4000 & 2.01 & 2.0209 & 0.54 \\
2 & 50 & 4.20 & 2 & 8000 & 2.05 & 2.0646 & 0.71 \\
\hline
\end{tabular}




\section{CONCLUSION}

Friction coefficient and wear rate of non-asbestos based rubber resin bonded metallic brake pad materials were evaluated under dry sliding contact conditions at elevated temperatures using a pin on disc tribo-tester. Following conclusions can be drawn. The EDS spectrum depicted the elemental composition of metallic (AF-22) material in order to compare and confirm the material. It was found that Coefficient of friction have been found in the range of 0.44 to 0.52 for this materials under consideration. The coefficient of friction under dry sliding condition increased with sliding distance but decreased with pressure for this material. Wear rate found in the range of 2.01 to $2.17 \mathrm{~mm}^{3} / \mathrm{N}$.m. Scanning electron microscopy images depicted chunk, segments and block images for non-asbestos materials.Taguchi's analysis method has enabled to analyze successfully the frictional and wear characteristics of compression moulded brake pad materials under sliding contact conditions with selected test parameters such as temperature, sliding velocity pressure and sliding distance. Ranking of the parameters has been done, and it was found that as per coefficient of friction concerns temperature contributes largely (95.37\%), sliding velocity (2.99 \%) followed by pressure (1.25 \%) and sliding distance $(0.39 \%)$. In order to determine wear rate, temperature contributed by $(82.96 \%$, pressure $(6.80 \%)$ followed by sliding velocity (5.77 \%) and sliding distance (4.48 \%) have statistical significance on friction as well as wear suggesting appropriate material plays very important role in brake pad application. However, detail research involving this material with influencing parameters and system variables to evaluate wear rate, stopping distance etc. have to be undertaken using simulative test conditions to predict the commercial use of such brake pad material in a specific braking operation.

\section{ACKNOWLEDGMENT}

The authors would like to acknowledge for the financial support received from R \& D research grant scheme by The Institution of Engineers (India). The Authors are thankful to the All India Shri Shivaji Memorial Society's College of Engineering Pune, for the facilities and support provided by them.

\section{REFERENCES}

1. Ademoh, N. A., Olabisi, A. I., "Development and Evaluation of Maize Husks asbestos-Free Based Brake Pad", Industrial Engineering Letters, 5(2), 67-80, (2015)

2. U. D. Idris, V. S. Aigbodion, I. J. Abubakar, C.I. Nwoye, "Eco-friendly asbestos free brake-pad:Using banana peels", Engineering Sciences, 27, 185-192, (2015)

3. K. K. Ikpambese, D. T. Gundu, L. T. Tuleun, "Evaluation of palm kernel fibers (PKFs) for production of asbestos-free automotive brake pads", Journal of King Saud University - Engineering Sciences, 28, 110-118, (2016)

4. S. G. Amaren, D. S. Yawas, S. Y. Aku , "Effect of periwinkles shell particle size on the wear behaviour of asbestos free brake pad", Results in Physics, 3, 109-114, (2013)

5. Johnson O Agunsoye, Sefiu A Bello, Adeola A Bamigbaiye, Kayode A Odunmosu, Isaac O Akinboye, "Recycled ceramic composite for automobile brake pad application", Journal of Research in Physics 39(1), 35-46, (2018)

6. Piyush Chandra Verma, Mattia Alemani, Stefano Gialanella, Luca Lutterotti, Ulf Olofsson, Giovanni Straffelini, "Wear debris from brake system materials: A multi-analytical characterization approach", Tribology International, 94, 249-259, (2016)
7. P. D. Neis, N. F. Ferreira, G. Fekete, L. T. Matozo, D. Masotti, "Towards a better understanding of the structures existing on the surface of brake pads", Tribology International, 105, 135-147, (2017)

8. Jens Wahlstrom, "A comparison of measured and simulated friction, wear and particle emission of disc brakes", Tribology International, 92, 503-511, (2015)

9. Vishal Mahale, Jayashree Bijwe, Sujeet Sinha, Wear, Influence of nano-potassium titanate particle on the performance of NAO brake-pad, (2017), Wear, 376-377, 727-737, (2017)

10. B. Surya Rajan, M. A. Sai Balaji, C. Velmurugan, "Correlation of field and experimental test data of wear in heavy commercial vehicle brake liners", Friction 5(1), 56-65, (2017)

11. Cong Ding, Hua Zhu, Guodong Sun, Yuankai Zhou, Xue Zuo, "Chaotic characteristics and attractor evolution of friction noise during friction process", Friction 6(1), 47-61, (2018)

12. Piyush Chandra Verma, Rodica Ciudin, Andrea Bonfanti, Pranesh Aswath, Giovanni Straffelini, Stefano Gialanella, "Role of the friction layer in the high-temperature pin-on-disc study of a brake material", Wear, 346-347, 56-65, (2016)

13. Hendre K. N., Bachchhav B. D., "Critical Property Assessment of NOVEL Brake Pad Materials BY AHP”, Journal of Manufacturing Engineering, Vol. 13, 148-151, (2018)

14. Ashok Kumar Ilanko, Srinivasan Vijayaraghavan, "Wear behavior of asbestos-free eco-friendly composites for automobile brake materials", Friction 4(2), 144-152, (2016)

15. Ranjit K. Roy, "Design of Experiments Using the Taguchi Approach", (1996)

\section{AUTHORS PROFILE}

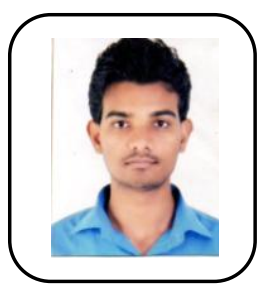

Kishor N. Hendre is a Post Graduate Scholar (Automotive Engineering) at the Department of Mechanical Engineering at All India Shri Shivaji Memorial Society's, College of Engineering, Pune. He is currently working on the project, Tribological characterization of brake pad materials.

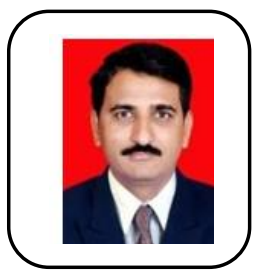

Dr. B. D. Bachchhav is currently working as a Professor and Head, Department of Mechanical Engineering, All India Shri Shivaji Memorial Society's, College of Engineering, Pune. He is having 18 years of teaching and research experience. He has more than 25 publications in various national and international journals. Dr. Bachchhav has completed three research projects funded by Savitribai Phule Pune University and also conducted various faculty development programs. His area of research is Manufacturing Engineering, Tribology, Metal forming and Non-conventional Machining. 